\title{
Analysing the Influence of Perceived Scarcity, Negative Feelings, and Status Consumption on Food Waste Among Consumers
}

\author{
Muhamad Azrin Nazri ${ }^{1 *}$, Nor Asiah Omar ${ }^{2 *}$, Suhaily Mohd Ramly ${ }^{3}$, Siti Ngayesah Ab Hamid \\ Azreen Jihan Che Mohd Hashim ${ }^{5}$ \\ ${ }^{1}$ Faculty of Economics and Muamalat, Universiti Sains Islam Malaysia, Negeri Sembilan, Malaysia \\ ${ }^{2,4}$ Centre of Value Creation and Human Well-being (INSAN), Faculty of Economics and Management, Universiti Kebangsaan Malaysia, Selangor, \\ Malaysia \\ ${ }^{3}$ Faculty of Business, Accountancy and Social Sciences, Kolej Universiti Poly-Tech MARA (KUPTM), Kuala Lumpur, Malaysia \\ ${ }^{5}$ Faculty of Economics and Muamalat, Universiti Sains Islam Malaysia, Negeri Sembilan, Malaysia
}

Received: 05/08/2020 Accepted: 02/10/2020 Published: 10/10/2020

\begin{abstract}
The purpose of this study is to examine the effect of perceived scarcity, negative feelings, and status consumption on food waste among consumers in Malaysia. A total of 258 questionnaires were collected via convenience sampling from customers who purchased food. The findings suggest that negative feelings and status consumption are significant and positively related to food waste. However, perceived scarcity shows no relationship to food waste. This study indicates that consumer's behaviors and motivations in buying food can lead to food waste. This study provides empirical and managerial contributions to the underlying factors that influence food waste among consumers. Due to the alarming level of food waste and limited research on consumer food waste behavior in the medium to a high-income group of countries such as Malaysia, there is an urgent call to conduct this study.
\end{abstract}

Keywords: Food Waste, Negative Feelings, Perceived Scarcity, Status Consumption

\section{Introduction}

In 2011, the Food and Agriculture Organization presented the estimate that around $1 / 3$ of the world's food is lost or wasted every year. Food waste is any food, and inedible parts of food, removed from the food supply chain to be recovered or disposed of. Wasted food is a considerable component of the world food system challenge [1]. Food waste can be categorised into three groups, which are food losses, unavoidable food waste and avoidable food waste [2]

Food is lost or discarded throughout the supply chain, from initial production to final use by the households [1]. The USDA's Economic Research Service (ERS) reported that 21 per cent of the 430 billion pounds of consumer-level food available in 2010 alone have been thrown away [3]. Consumers dumped 244.5 billion kilocalories per day, 789 kilocalories per capita [3]. Roughly onethird of food produced for human consumption is lost or wasted globally [4]. The most common reasons customers throw away food are expiry dates, foods that look, smell, degust poor, mold or too much time in the refrigerator or cupboard [5]. Fruit and vegetables, post-prepared leftovers, bakery products, dairy products, and eggs are the most popular food being thrown away
[5]-[6]. Many activities make consumers more likely to produce food waste, such as shopping in large supermarkets, shopping infrequently, and not preparing menus or making shopping lists [5]-[7]. The same study also found that consumers do not generally regard food waste as an environmental problem. Food waste is also recognized as a major issue for global environmental, economic and health security [7]-[8]. A major challenge that faces the international community is to provide safe for over 9.1 billion people by the year [9]. According to FOA (2011) report, 32 percent of the world-produced food was lost or wasted in 2009. According to the US Environmental Protection Agency (EPA), food waste currently represents the single largest type of waste entering landfills. Wasted food leads to over utilization of water and fossil fuels and increasing greenhouse gas emissions, i.e. methane and carbon dioxide arising from degradation of food in landfills [10]. The gross carbon footprint of lost and wasted food, excluding land use, is measured at 3.3 billion tons of $\mathrm{CO}_{2}$ equivalent, according to a recent study by the FAO.

The issue of food wastage is also prevalent in Southeast Asia and showing significant implications for the region's food, environmental and economic security [11]. It is estimated that 33

Corresponding author: Muhamad Azrin Nazri, Faculty of Economics and Muamalat, Universiti Sains Islam Malaysia, Negeri Sembilan, Malaysia. E-mail: muhdazrin@usim.edu.my 
percent of food in the world is wasted in Southeast Asia [12]. Target [11]. There are effective measures to prevent and reduce food waste, but in Southeast Asia they are not widely implemented. The RSIS Center for Non-Traditional Security (NTS) Studies hosted the August 2012 Expert Working Group Meeting to discuss food from Southeast Asia in connection with these issues. This policy brief is based on the meeting's results and presents some policy recommendations for governments in Southeast Asia to tackle urban and rural food waste [11]. Specifically, domestic waste in Malaysia accounts is the main contributor which is $64 \%$. The share of industrial waste is $15 \%$, followed by agricultural waste and building waste and institutional waste. It was reported that on average a household in Malaysia throws away around $0.5-0.8 \mathrm{~kg}$ uneaten food per day [13]. Statistics from Malaysia's Solid Waste Corporation (SWCorp) showed that Malaysia's food waste exceeded 15,000 tons per day in 2015 and for that amount of food waste, the food was enough for almost 10 Million people, including 3,000 tons that were still fit for consumption and should not have been discarded [1]. Clearly, Malaysian solid waste contains a large amount of food waste, and the volume has recently been estimated to hit 63.1 percent in 2008 (Siwar, 2008) and 74 percent specifically in Kuala Lumpur (Malaysia's capital), which is mostly disposed of at landfills.

Generally, food waste is usually associated with behaviors such as negligence or conscious discard decisions [14]. The behavior of consumers in food waste may be systematically related to the drivers of food purchasing decisions, which in turn are based on intrinsic and extrinsic attributes of food [15]. Food waste becomes one of the biggest concerns in this modern era, as it causes unfavorable issues to the environment, economic and social consequences on the sustainability of the food sector around the globe [16]. Furthermore, food waste is also known as the removal from food supply chain which is suitable for consumption, or due to it was expired or spoiled because of consumer behavior itself which involve urgency to buy, perceived scarcity or negative feelings; whereas food loss is defined as the reduction in quantity or quality of food [4]. Both food loss and food waste are strongly related as decreasing each of them will help to increase food supply to people who need food and also increase positive impact to the environment physically, socially and economically. With millions of people all over the world struggling to find enough food to eat for survive, the fact that millions of tons of food are tossed out every year can be surprising.

The wastage of food occurs at all stages of the life cycle of food, starting from harvesting, through manufacturing and distributing and finally consumption, but the largest contribution to food waste is from homes [17][18][19]. Sometimes, consumer's behaviors and motivations such as status consumption in buying food will make an impact on consumer's emotion and attitudes (anticipated regret, utilitarian attitude, hedonic attitude). According to the literature review, status consumption is "the motivational process by which individuals strive to improve their social standing through the conspicuous consumption of consumer products that confer and symbolize status both for the individual and surrounding significant others." [20]. Empirical studies are still lacking despite this growing concern about food waste behavior at the consumer level [21][22][23].

\section{Literature Review and Hypotheses Development}

Status consumption is the purchase, use and consumption of products to gain status among peers and society [24]. Status- conscious consumers seek self-satisfaction from the product, as they tend to use products that have visible brand. This allows them to gain a certain level of self-identity and association to a specific class [25], consumers will place their desire rather than their necessity in purchasing goods or services. This kind of purchasing behavior link to luxury, glamour, leisure, abundance and waste [26].

People with bad emotion are in uncontrolled condition which will lead towards purchasing unnecessary items and tend to hoard the particular products [27]. In addition, individual with negative thought lingering in their minds will restrain themselves to consume the food [28], [29]. All the negative feeling during food consumption such as distress, feelings of shame (e.g., drawing attention due to their manner of eating) and frustration (e.g., due to avoiding some of their favorite foods) will let an individual leave their food unfinished [30]. Furthermore, consumer have negative feeling towards food waste although in short period they are like to throw food and feel guilty afterwards [31].

Consumers portrays that scarce objects are valuable. They often infer value in a product that has limited availability or is promoted as being scarce [32]. A limited-quantity scarcity was on a first come first serve basis that trigger consumer to buy immediately as they have no clue on the stock availability [33]. A scarce product was perceived as more desirable as customer hypothetically think that they need the product in the future [34]. Thus, it makes the consumers comprehend that if they did not purchase the product right away, then they would not have any chance to get it next time. Scarcity conditions would pursue consumers to buy the product immediately [35]. These are the hypotheses $(\mathrm{H} 1-\mathrm{H} 3)$ developed for the study. The research framework is shown on Figure 1.

H1: Perceived scarcity positively influences food waste. $\mathrm{H} 2$ : Negative feelings positively influences food waste.

H3: Status consumption positively influences food waste.

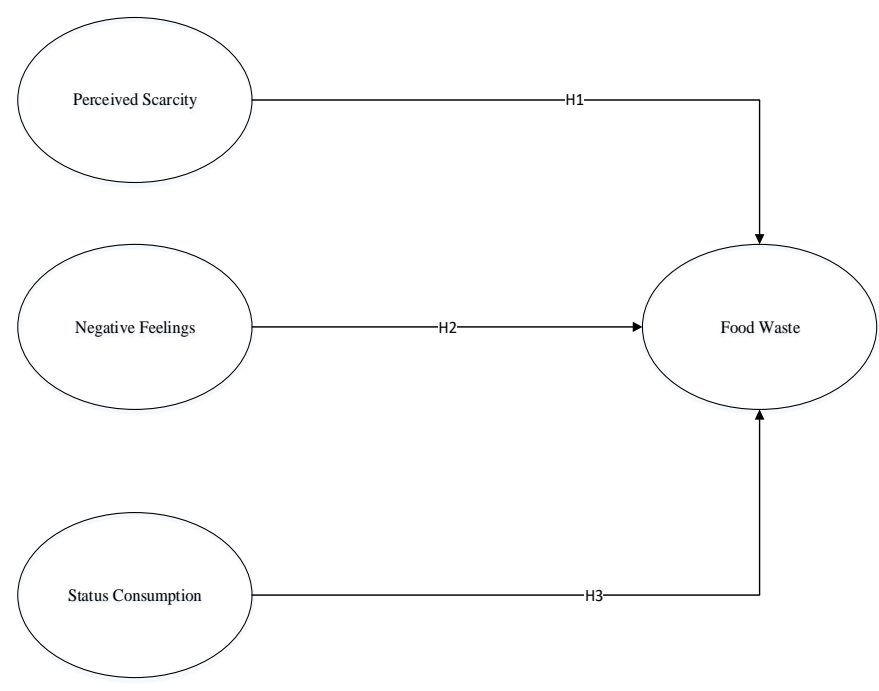

Figure 1: Research Framework 


\section{Research Methodology}

A. Sampling and Research Procedure

In this study, the data was collected using primary method which is using questionnaire. It was done in The National University of Malaysia (UKM). Respondents were given a self-administered questionnaire to answer. A total of 200 valid questionnaire was collected from the respondents and used for data analysis.

\section{B. Research Instrument}

All questions in the survey were adopted and adapted from past studies. All items were measured using 7-point Likert scale (1=strongly disagree, 2=disagree, 3 =somewhat disagree, $4=$ neutral, $5=$ somewhat agree, $6=$ agree, $7=$ strongly disagree).

\section{Data Analysis}

In this study food waste stands as the dependent variable and the remaining variables: perceived scarcity, negative feelings, and status consumption represent the independent variables. The results are shown in Table 1 , the value of $R^{2}=0.174$, which implies 17.4 percent of variance in food waste are likely explained by perceived scarcity, negative feelings, and status consumption. As indicated in Table1, status consumption, and negative feelings have significant positive influence on the food waste. Hence supporting $\mathrm{H} 2$ and $\mathrm{H} 3$. However, perceived scarcity is not significantly related to food waste. Thus, $\mathrm{H} 1$ is not supported. On examining the value of Beta, it could be observed that status consumption has most crucial influence on food waste followed by negative feelings.

This result of the research validates past studies that indicate negative emotions lead to high food intake in response to positive emotions [36]. Several other researchers also suggested that sadness enhances food indulgence [37][38] and impulse buying [39][40]. In addition, past studies also pointed that, as people higher on materialism they are not only found to have more favorable attitudes toward spending [41] but have also been linked to wasting money on relatively unimportant possession [42].

Table 1: Regression results between perceived scarcity, negative feeling and status consumption

\begin{tabular}{|l|l|}
\hline Independent Variables & Standardized Beta \\
\hline Perceived scarcity & $0.174^{\mathrm{ns}}$ \\
\hline Negative feelings & $0.174^{*}$ \\
\hline Status consumption & $0.227^{*}$ \\
\hline $\mathrm{R}^{2}$ & 0.174 \\
\hline Adjusted $\mathrm{R}^{2}$ & 0.164 \\
\hline f-value & 17.866 \\
\hline
\end{tabular}

Note: $* \mathrm{p}<0.05 ; \mathrm{ns}=$ not significant

\section{Conclusions}

Based on the research findings, it can be concluded that negative feelings and status consumption are significantly related to food waste. However, perceived scarcity has no significant relationship with food waste. The negative feeling during food consumption will let an individual leave their food unfinished. In other word, negative feelings tend to influence consumers to make more food consumption to soothe their bad mood, this will lead to more food purchase that may cause food wastage. Status consumption is also related to food waste as consumers will place their desire more than their necessity in purchasing goods or services that ultimately leads to waste.

Although this study has few significant contributions, it still has limitations. This study has investigated only three variables and employed cross sectional data. Thus, it is recommended for future research to include more variables in the framework and employ a qualitative method that may possibly generate more information on the present study.

\section{Acknowledgment}

The author would like to thank Malaysia Research University Network (MRUN) in providing the grant: EP-2019-004/ UPM.800-4/11MRUN/2019/5539140 and USIM/YTI/FEM/052002/41618 in assisting this research.

\section{Ethical issue}

Authors are aware of, and comply with, best practice in publication ethics specifically with regard to authorship (avoidance of guest authorship), dual submission, manipulation of figures, competing interests and compliance with policies on research ethics. Authors adhere to publication requirements that submitted work is original and has not been published elsewhere in any language.

\section{Competing interests}

The authors declare that there is no conflict of interest that would prejudice the impartiality of this scientific work.

\section{Authors' contribution}

All authors of this study have a complete contribution for data collection, data analyses and manuscript writing.

\section{References}

1 T. F. S. Teixeira, Ł. M. Grześkowiak, S. Salminen, K. Laitinen, J. Bressan, and M. do C. Gouveia Peluzio, "Faecal levels of Bifidobacterium and Clostridium coccoides but not plasma lipopolysaccharide are inversely related to insulin and HOMA index in women," Clin. Nutr., vol. 32, no. 6, pp. 1017-1022, 2013.

2 N. B. D. Thi, G. Kumar, and C. Y. Lin, "An overview of food waste management in developing countries: Current status and future perspective," Journal of Environmental Management, vol. 157. pp. 220-229, 2015.

3 J.C. Buzby, H. F. Wells, and J. Hyman, "The estimated amount, value, and calories of postharvest food losses at the retail and consumer levels in the United States," in Food Loss in the United States: Selected Analyses, 2014, pp. 1-42.

4 FOA, "The State of Food and Agriculture Social protection and agriculture: Breaking the cycle of rural poverty," Rome, 2015.

5 J. Jörissen, C. Priefer, and K. R. Bräutigam, "Food waste generation at household level: Results of a survey among employees of two European research centers in Italy and Germany," Sustain., vol. 7, no. 3, pp. 2695-2715, 2015.

6 B. Lyndhurst, "Public understanding of sustainable energy consumption in the home," 2007.

7 WRAP, "Household Food and Drink Waste in the UK," London, 2007.

8 J. Sobal and M. K. Nelson, Sobal, J., \& Nelson, M. (2003). Food waste. Encyclopedia of food and culture, 1, 28-29. 2003.

9 FOA, "The future of food and agriculture: Trends and challenges," 2017.

10 K. D. Hall, J. Guo, M. Dore, and C. C. Chow, "The progressive increase of food waste in America and its environmental impact," PLoS One, vol. 4, no. 11, 2009. 
11 P. Teng and S. Trethewie, Tackling urban and rural food wastage in Southeast Asia: Issues and interventions. S. Rajaratnam School of International Studies, 2012.

12 Z. Yang et al., "Potential application of gasification to recycle food waste and rehabilitate acidic soil from secondary forests on degraded land in Southeast Asia," J. Environ. Manage., vol. 172, pp. 40-48, 2016.

13 C. P. Chien Bong et al., "Review on the renewable energy and solid waste management policies towards biogas development in Malaysia," Renew. Sustain. Energy Rev., vol. 70, pp. 988-998, 2017.

14 B. Lipinski, C. Hanson, J. Lomax, L. Kitinoja, R. Waite, and T. Searchinger, "Reducing Food Loss and Waste," 2013.

15 Canadian Agriculture and Agri-Food System, "An Overview of the Canadian Agriculture and Agri-Food," 2015.

16 T. Garnett, "Where are the best opportunities for reducing greenhouse gas emissions in the food system (including the food chain)?," Food Policy, vol. 36, no. SUPPL. 1, 2011.

17 EPRS, "Tackling food waste The EU's contribution to a global issue," 2016.

18 H. Williams, F. Wikström, T. Otterbring, M. Löfgren, and A. Gustafsson, "Reasons for household food waste with special attention to packaging," J. Clean. Prod., vol. 24, pp. 141-148, 2012.

19 J. Thøgersen, "Wasteful food consumption: Trends in food and packaging waste,” Scand. J. Manag., vol. 12, no. 3, pp. 291-304, 1996.

20 J. K. Eastman, R. E. Goldsmith, and L. R. Flynn, "Status Consumption in Consumer Behavior: Scale Development and Validation," J. Mark. Theory Pract., vol. 7, no. 3, pp. 41-52, 1999.

21 D. Evans, "Beyond the Throwaway Society: Ordinary Domestic Practice and a Sociological Approach to Household Food Waste," Sociology, vol. 46, no. 1, pp. 41-56, 2012.

22 V. Stefan, E. van Herpen, A. A. Tudoran, and L. Lähteenmäki, "Avoiding food waste by Romanian consumers: The importance of planning and shopping routines," Food Qual. Prefer., vol. 28, no. 1, pp. 375-381, 2013

23 V. Stancu, P. Haugaard, and L. Lähteenmäki, "Determinants of consumer food waste behaviour: Two routes to food waste," Appetite, vol. 96, pp. 7-17, 2016 .

24 M. Teah, I. Phau, and Y. an Huang, "Devil continues to wear 'counterfeit' Prada: A tale of two cities,” J. Consum. Mark., 2015.

25 J. K. Eastman and K. L. Eastman, "Perceptions Of Status Consumption And The Economy,” J. Bus. Econ. Res., vol. 9, no. 7, p. 9, 2011.

26 A. R. C. Rocha, A. da Rocha, and E. Rocha, "Classifying and classified: An interpretive study of the consumption of cruises by the ‘new’ Brazilian middle class,” Int. Bus. Rev., 2016.
27 M. Noh and H. M. R. ul Hasan, "Moderating effect of personality traits on relationships between retail therapy, compulsive buying, and hoarding for fashion products,” J. Glob. Fash. Mark., 2017.

28 E. Sthapit, P. Björk, and D. N. Coudounaris, "Emotions elicited by local food consumption, memories, place attachment and behavioural intentions," Anatolia, 2017.

29 F. Bastami, F. Zamani-Alavijeh, and F. Mostafavi, "Factors behind healthy snack consumption at school among high-school students: A qualitative study," BMC Public Health, 2019.

30 L. Remijn, L. van den Engel-Hoek, T. Satink, B. J. M. de Swart, and M. W. G. Nijhuis-van der Sanden, "'Everyone sees you sitting there struggling with your food': experiences of adolescents and young adults with cerebral palsy," Disabil. Rehabil., 2019.

31 S. V. Russell, C. W. Young, K. L. Unsworth, and C. Robinson, "Bringing habits and emotions into food waste behaviour," Resour. Conserv. Recycl., 2017.

32 R. B. Cialdini, Influence : Science and Practice Influence : Science and Practice, no. July. 2014.

33 P. Aggarwal, S. Jun, and J. Huh, "Scarcity messages: A consumer competition perspective," J. Advert., vol. 40, no. 3, pp. 19-30, 2011.

34 J. M. Jung and J. J. Kellaris, "Cross-national differences in proneness to scarcity effects: The moderating roles of familiarity, uncertainty avoidance, and need for cognitive closure," Psychol. Mark., 2004

35 S. Gupta and J. W. Gentry, "'Should I Buy, Hoard, or Hide?' Consumers' responses to perceived scarcity," Int. Rev. Retail. Distrib. Consum. Res., vol. 29, no. 2, pp. 178-197, 2019.

36 T. Van Strien et al., "Emotional eating and food intake after sadness and joy," Appetite, vol. 66, pp. 20-25, 2013.

37 M. P. Gardner, B. Wansink, J. Kim, and S. B. Park, "Better moods for better eating?: How mood influences food choice," J. Consum. Psychol., vol. 24, no. 3, pp. 320-335, 2014.

38 N. Garg, B. Wansink, and J. J. Inman, "The influence of incidental affect on consumers' food intake," J. Mark., vol. 71, no. 1, pp. 194206, 2007

39 J. Z. Sneath, R. Lacey, and P. A. Kennett-Hensel, "Coping with a natural disaster: Losses, emotions, and impulsive and compulsive buying," Mark. Lett., vol. 20, no. 1, pp. 45-60, 2009.

40 S. J. Yoon, "Antecedents and consequences of in-store experiences based on an experiential typology," Eur. J. Mark., vol. 47, no. 5, pp. 693-714, 2013.

41 R. B. Gardarsdóttir and H. Dittmar, "The relationship of materialism to debt and financial well-being: The case of Iceland's perceived prosperity," J. Econ. Psychol., vol. 33, no. 3, pp. 471-481, 2012.

42 Bae, "Understanding Ethical Consumers: Assessing the Moderating Effects of Price Sensitivity, Materialism, Impulse Buying Tendency, and Clothing Involvement," Colorado State University, 2013. 